\title{
La pedagogía patrística: aportes a la transmisión del saber teológico
}

\author{
Edith González Bernal*
}

Recibido: 15 de marzo 2013 • Aprobado: 14 de mayo de 2013

\section{Resumen}

Este artículo* presenta una aproximación a la pedagogía patrística teniendo como punto de referencia a San Clemente de Alejandría y a San Agustín de Hipona. Se ha optado por estos dos padres de la Iglesia debido a que en sus escritos desarrollan grandes temáticas en las que la pedagogía ocupa un aspecto importante en la transmisión de sus contenidos. Igualmente la opción por acercanos a su teología y a su pedagogía, es una opción más por conocer la experiencia de Dios que ellos nos transmiten, y por la preocupación que ellos mostraron para que otras personas vivan lo que experimentaron. En este sentido podemos hablar de una pedagogía en la transmisión del saber teológico. Es claro que para los Padres de la Iglesia, la pedagogía viene dada por el arte de conducir a los otros hacia el conocimiento, de esta manera, su intención fue buscar hacer que lo que escribieron tuviera una intencionalidad pedagógica, de descubrimiento de aquello que está dentro del ser humano, de ese "algo" que lo habita y que necesita ser sacado a la luz. En este sentido el artículo, en un primer momento, contextualiza el saber teológico como un saber que es transmitido a través de procesos pedagógicos y, en segundo momento, desarrolla una aproximación a la experiencia de Dios en los Padres; describe y analiza por separado el aporte que cada uno de ellos ofrece en la transmisión del saber teológico y finalmente se presentan las conclusiones.

Palabras clave: pedagogía, patrística, saber teológico y experiencia de Dios.

* Candidata doctorado en Teología. Pontificia Universidad Javeriana. Doctora en Ciencias de la Educación. Universidad Pedagógica y Tecnológica. Profesora de la Facultad de Teología de la Pontificia Universidad Javeriana. Correo electrónico: edith.gonzalez@javeriana.edu.co

* Este es un artículo de reflexión que ofrece algunos aportes en la producción de la teología como una disciplina que se transmite en ámbitos educativos. 


\title{
Patristic pedagogy: contributions \\ to the transmission of theological knowledge
}

\begin{abstract}
Abstact
This article presents an approach to patristic pedagogy taking as point of reference St. Clement of Alexandria and St. Augustine of Hippo. These two fathers of the Church have been chosen because in their writings they develop major themes in which pedagogy occupies a significant aspect in the transmission of their contents. Also the option of getting closer to their theology and pedagogy, is another option for knowing the experience of God they transmit, and their concern they showed so that other people would live what they experienced. In this regard we can speak of a pedagogy in the transmission of theological knowledge. Clearly for the fathers of the Church the pedagogy is given by the art of leading others towards the knowledge, this way, their intention was to seek that what they wrote had a pedagogical purpose, of discovering that which is inside the human being, that "something" that inhabits it and needs to be brought to light. In this regard the article firstly contextualizes theological knowledge as a knowledge that is transmitted through pedagogical process and secondly develops an approach to the experience of God in the fathers, describes and analyzes separately the contribution that each one of them offers in the transmission of theological knowledge and finally presents the conclusions.
\end{abstract}

Keywords: Pedagogy, patristic theological knowledge and experience of God.

\section{El saber teológico. Un saber que se transmite mediante procesos pedagógicos}

En la producción del saber teológico contemporáneo, se percibe que la situación actual por la que atraviesa la transmisión o la enseñanza de la teología, tiene serios cuestionamientos en el orden de la relación teología y pedagogía. Abundan textos (libros, investigaciones doctorales, artículos, homilías) de teólogos católicos y de otras denominaciones religiosas que señalan la necesidad de volver a la experiencia de Dios para nutrir el discurso teológico. Abogan por la necesidad de llevar a cabo una reflexión pedagógica que permita hablar en un lenguaje comprensible y actualizado sobre el acontecer de Dios en el ser humano.

Constantemente nos interrogamos por la función del saber teológico, como un saber que da sentido a la vida y por la labor del teólogo propiamente. González 
Faus $^{1}$, plantea seriamente la manera como se está haciendo teología, sin dar un paso atrás a lo que es la experiencia fundante, al compromiso y a la responsabilidad que tiene el teólogo con la Iglesia y con la sociedad. Asimismo Duquoc ${ }^{2}$, señala que la cultura moderna no aprecia ni valora el trabajo de la teología, porque los teólogos han sido condenados al exilio.

Actualmente, los teólogos ${ }^{3}$ reconocen que para hacer teología cristiana se necesita haber sentido y experimentado algo de Jesucristo. Se afirma que la experiencia precede a la teología como primer acto del silencio de Dios y de la praxis, concibiéndola como una forma concreta de vivir el Evangelio conforme a la fuerza del Espíritu Santo. En este sentido la teología se fundamenta en la experiencia de fe, en la reflexión, en la sabiduría, en el silencio, en la escucha, en el camino de conversión, de gratuidad y libertad.

Si bien el teólogo es un hombre o mujer ubicados en un contexto, conocedores de la condición y sabedores que grandes preguntas interrogan la existencia y tocan el quehacer teológico; pues como bien dice Heidegger «La existencia, es precisamente el drama de nuestro vivir, drama sin solución en tanto es vivido

1 González Faus, J. I. (1985). La libertad de palabra en la Iglesia y en la teología. Santander: Sal Terrae, 75-76. «los teólogos han dejado descomponer la Tradición en el féretro tenebroso de la repetición. Desde hace siglos, los teólogos sois sólo compiladores de sinopsis, manipuladores de manuales, registradores de lugares comunes, tediosos comentaristas, glosadores, exhumadores, apostilladores y remasticadores de antiguos textos venerados, Probos, diligentes, sapientes repetidores, pero nada más que repetidores. ¿No habéis pensado nunca que los manjares recalentados acaban por ser aborrecidos hasta por los menos golosos, que los alimentos cocinados y recocinados en las viejas ollas y con las mismas salsas terminan, a la larga, por hastiar a los paladares más pacientes? No es verdad que todo esté dicho y que sólo nos quede ser portavoces de los muertos. Cada siglo inicia de nuevo el camino del espíritu. Salid alguna vez al aire libre, escuchad las voces que se alzan de las almas que padecen hambre de certeza; no creáis rebajaros por aprender algo incluso de los no teólogos».

2 Duquoc, C. (2006). O.P. El destierro de la teología. El reto de su supervivencia en la cultura contemporánea. Bilbao: Mensajero, 10-11.

3 Gutiérrez, G. (1985). Beber en su propio pozo. Salamanca: Sígueme, p. 177« El hablar sobre Dios (teo-logía) viene después del silencio de la oración y del compromiso. La teología será un hablar constantemente enriquecido por un callar. Un discurso que hunde sus raíces en una fe vivida en comunión eclesial, e inserta por eso en una historia de transmisión y acogida del mensaje cristiano». Vilanova, E. (1992). Para comprender la teología. Navarra: Editorial Verbo Divino, p. 20. «La teología como esfuerzo reflexivo, se ha separado de la experiencia de fe que está en su base, de tal modo que prácticamente ha dejado de ser una aventura, un itinerario interior atento a la Revelación, de la cual nace, y ha convertido la Revelación en un simple presupuesto en el cual se apoya». González de Cardedal, O. (2008). El quehacer de la teología. Salamanca: Sígueme, p. 34. Este autor precisa que hacer teología es un acto segundo en el sentido de que se tiene primero que «oír, atender y entender, inteligir, interpretar, sistematizar y obedecer lo que Dios diga de sí mismo y del hombre, mediante acciones y palabras en la historia». 
en su inmediatez de dato vital, que en sí no se explica, drama que es profunda inquietud y angustia y nos empuja a menudo a la exaltación de nuestro puro egoísmo o a una serie de acciones que no son sino la expresión de nuestra pura y simple voluntad de conservación, drama que no es otra cosa que el continuar en nosotros de nuestra vida biológica o utilitaria o económica, continuada así, sin un por qué, sin que nosotros podamos atribuirle un fin, una explicaciónn cualquiera, una justificación» ${ }^{4}$.

De ahí, que el saber teológico frente a este drama se ve abocado a dar razones de sentido a la existencia, a la esperanza y al reconocimiento de la condición humana; y entonces es aquí donde entra en escena la pedagogía que reclama una teología, de manera que se pueda orientar al ser humano en la vivencia cristiana, más allá de normas y preceptos, y más allá de los actos humanos que parecieran determinar en ellos su bondad y su maldad.

El mundo que experimentamos es un mundo fraccionado para conocerlo y desentrañarlo, lo que da paso a diferentes maneras de abordar y responder las preguntas por el sentido hondo de la vida que tienen los hombres y mujeres. Dentro de los múltiples desarrollos de la teología, el recurso simbólico, poético y sapiencial, cobra importancia entre las nuevas formas de contextualizar la teología. De ahí que pensar en una relación teología-pedagogía, nos permitirá reescribirla de manera que suscite en el ser humano un espacio para la sabiduría, para la fe, para la contemplación y para el entendimiento. En una concepción de un Dios que busca hacerse oír, y que muy bien lo expresa Vaticano II, en lo que afirma que el quehacer de «los pastores y teólogos es escuchar con la ayuda del Espíritu Santo, y discernir e interpretar las varias voces de nuestro tiempo, y valorarlas a la luz de la palabra divina, para que la verdad revelada, pueda ser mejor recibida, mejor comprendida, y expresada en forma más adecuada» (GS 44).

El quehacer teológico se lleva a efecto narrando la historia, comunicando lo que se ha vivido: «La verbalización de la experiencia de fe es un indicio de su carácter genuino, Dios no llama al ser humano a permanecer mudo, sino para a anunciarlo y dar testimonio de Él. Quien ha tenido la experiencia de Dios sabe lo difícil que es formularla en palabras, pero a la vez sabe que no está autorizado a guardarse esa experiencia para sí» ${ }^{5}$. En este sentido, se puede hablar de una

4 Heidegger, Martín. (1992). ¿Qué es la metafísica? Y otros ensayos. Traducción de Xavier de Zubiri, Buenos Aires: Fausto, p. 39.

5 Schneider, M. (s.f). Teología como biografía. Una fundamentación dogmática. Op Cit. p 57. 
teología narrativa ${ }^{6}$ que no se fundamenta en conceptos abstractos, sino en el relato vivo, participado y compartido de la experiencia de Dios presente en las culturas, razas, credos y clases sociales y que hace posible un sentimiento como lo describe San Pablo: «No hay ya judío, ni griego, ni esclavo ni libre, ni hombre, ni mujer, ya que todos vosotros sois uno en Cristo Jesús» (Gal 3,28).

Lo anterior expresa la necesidad de una renovación de la teología, una revisión de las fuentes fundantes, una experiencia de fe que lleve a un quehacer teológico que en palabras de Barth significa «El trabajo teológico se distingue de los otros por el hecho de que aquel que quiere realizarlo no puede llegar a él, descansado, desde unas cuestiones ya solucionadas, desde unos resultados ya seguros... sino que se ve obligado cada día y cada hora a volver a empezar por el principio» ${ }^{7}$. De igual manera, Sudbrack señala en sus estudios la importancia de establecer un «puente entre el mensaje enseñado por la teología y la experiencia [...] ese puente necesita cimientos de ambos lados, del lado de la reflexión, en la cabeza, y del lado de la experiencia, en el corazón» ${ }^{8}$.

De esta manera, el quehacer teológico implica acción pedagógica en cuanto arte de conducir y de guiar, de pensar y reflexionar sobre la experiencia que se ha tenido y la manera como se debe comunicar. Pues se trata de transmitir a los hombres y mujeres la Palabra de Dios que ha sido revelada. Sin embargo, no se trata de transmitir solo una doctrina sino que: «debe ser mediadora de una presencia, que a la manera de San Agustín es el persuadere, el cual no se trata de un convencimiento intelectual respecto de una doctrina, sino suscitar en el corazón del oyente la adhesión de su persona a la persona de Jesucristo y ello se produce en el espacio sagrado de una tierra en la que hay que descalzarse» ${ }^{9}$.

Ahora bien, entendemos que la fe no es objeto de aprendizaje, sino de experiencia, la experiencia del encuentro con Jesús, que no es un encuentro con verdades, porque como dice Unamuno, «Perdí mi fe pensando en los dogmas, en los

6 Una comprensión básica y general de lo que entendemos por teología narrativa se puede ver en Siciliani Barraza, J. M. Teología narrativa, pp 23-187; Tolmie, D. F. Narratology and Biblical Narratives: a practial guide, pp 1-9; Goldberg, M. Theology and Narrative. A critical Introduction, pp 11-38.194-240; Navarro Puerto, M. Cuando la Biblia cuenta. Claves de la narrativa bíblica, pp 5-11.

7 Barth, K. (2006). Introducción a la teología evangélica. Barcelona: Sígueme, p. 152.

8 Sudbrack, J. (2004). El espíritu es concreto: la espiritualidad desde una perspectiva cristiana. Bilbao: Mensajero, p. 39. El autor busca mostrar una espiritualidad que es manifestación del Espíritu Santo y que está unido a realidades concretas como la Creación o la Encarnación.

9 Durwel, F. X. (1972). La presencia de Jesucristo en la predicación. España, Salamanca, p. 34. 
misterios como dogmas, la recobro meditando en los misterios, en los dogmas como misterios» ${ }^{10}$. De ahí, que la fe no es una certeza que se pruebe con argumentos, sino que es experiencia, pero, es a partir de esa experiencia, prácticamente incomunicable, que ensayamos un discurso, y para ello, la pedagogía es el vehículo en el quehacer teológico que nos permite preguntarnos y respondernos por el sentido de nuestra vida, por el lugar de nuestro ser en el cosmos, por el ejercicio de nuestra libertad, por el sentido de nuestros actos, por el impacto de nuestras decisiones, por nuestras ansias infinitas de infinitud y por nuestra relación con el Trascendente.

En la perspectiva de un trabajo académico que parte del presupuesto de fe, de sentirse tocado y habitado al estilo como lo describe Pascal: «no me buscarías si no me hubieses encontrado ya» (de los "Pensamientos" 355, borradores inconclusos), nos permite ver y sentir que la existencia tiene un sentido pleno, y que a partir de allí, solo entonces el mundo deja de ser un absurdo y se convierte en un llamado a una plenitud del ser. Solo un mundo infinito en sus dimensiones, puede hacer vibrar en nosotros las ansias de infinitud. Los hombres y las mujeres creyentes, nos reconocemos finitos pero aspiramos a una infinitud, no abstracta sino concreta, encontramos entonces en la fe y en la contemplación un punto de partida para descubrirnos a nosotros mismos y para situarnos dentro del universo.

\section{Aproximación a la experiencia de Dios en los padres de la Iglesia y sus aportes pedagógicos}

Los padres ${ }^{11}$ de la Iglesia nos dejan ver la huella del amor de Dios en los seres humanos y el efecto que produce en su corazón. Conviene precisar que aquí no se pretende hacer un estudio exhaustivo sobre los padres de la Iglesia; San Clemente

10 Unamuno, M. (1966). Diario íntimo. Obras completas, t. 8, Madrid: Biblioteca Castro Fundación José Antonio de Castro, p. 865.

11 Hamman, A. (2009). Para leer los padres de la Iglesia. Bilbao. En su introducción, señala que el término padre designaba, primero en la Biblia y luego en el cristianismo primitivo, al maestro que enseña a un discípulo llamado también hijo de aquel que enseña. Como la enseñanza de la Iglesia competía por derecho al obispo, éste recibió el título de padre. Por extensión, el mismo título les fue aplicado a los monjes y a los ascetas, considerados formadores de discípulos. Por esta razón el título se aplica de modo particular a aquellos que, formados en su mayor parte en la cultura grecolatina clásica y convertidos en edad adulta, fueron monjes, sacerdotes, obispos y ante todo pastores de la Iglesia. Así el estudio de los padres se llama patrología o patrística. Este término fue creado en 1653 por le luterano Jean Gerhard. Designa el estudio de las literaturas cristinas antiguas. Generalmente se reserva el término para el estudio doctrinal y la historia de las ideas. 
y San Agustín, ${ }^{12}$ puesto que el interés está en mostrar los fundamentos que constituyen la experiencia de Dios y sus aportes en la transmisión de su saber. Ellos en sus escritos han señalado itinerarios de vida espiritual, producto de una experiencia personal que es comunicada. Lo que los padres enseñaron descansa en su experiencia de ser oyentes de la palabra y trasmisores de ella, mediante una vida que significó un itinerario de perfección y de verdadera gnosis. La novedad está en que lo que se transmitió fue fruto de una experiencia de encuentro personal con Dios, y que su intencionalidad fue mover a los otros a creer y a seguir un camino que conduce a Dios a través de Jesús.

\section{La experiencia de Dios en Clemente de Alejandría.}

En Clemente de Alejandría, ${ }^{13}$ su amplio conocimiento filosófico y teológico es la plataforma para desarrollar un programa de conocimiento y apertura a Dios, que supone un itinerario del hombre hacia Él. Clemente, deja ver a través de su experiencia de Dios, un conocimiento que va más allá de la fe, un conocimiento teológico y de contemplación de Dios. En este sentido, apuesta por un trabajo que tiene el cristiano de asumir un camino al estilo del pedagogo. Considera que la misión del pedagogo en la realización de la obra salvadora de Jesús comprende cuatro operaciones: «crearnos, perfeccionarnos, regenerarnos y educarnos (...) lo que significa llevar a cabo una acción pedagógica de: exhortación, educación e instrucción». ${ }^{14}$ Para Clemente, ocupa especial importancia el Logos que incita a un cambio de vida y a la búsqueda de la verdad. El Logos, corrige y guía las acciones, instruye en la verdad, persuade, convierte, educa y enseña.

12 Se han elegido a estos dos autores por las siguientes razones: Un padre griego y un padre latino, lo que nos permite contrastar en sus escritos la manera como ellos dan a conocer su experiencia de Dios. Los dos padres dejan ver un sello constante y apasionado por enseñar lo que han oído, visto y sentido, es decir hay una intencionalidad pedagógica de llevar al oyente hacia el conocimiento de Dios: El pedagogo y los stromata en San Clemente de Alejandría y De Trinitate, De magistro, las confesiones en San Agustín. En los dos es fuerte el señalamiento de la gnosis, se llega a Dios por el conocimiento.

13 Laporte, Jean. Los padres de la Iglesia. Padres griegos y latinos en sus textos. En el capítulo II trae a Clemente de Alejandría en su biografía y comenta los textos de: Protéptico, el Pedagogo y los Stromata. Se dice que nació en el año 150 de padres paganos, probablemente en Atenas, se convirtió a la fe cristiana. Hizo grandes viajes por el sur de Italia, por Siria y Palestina, con intención de escuchar los maestros cristianos más célebres.

14 De Alejandría, C. (1994). El pedagogo. Edición bilingüe preparada por Marcelo Merino y Emilio Redondo. Madrid: Editorial Ciudad Nueva, p. 29. 
Señala que «El verbo de Dios se ha hecho carne para educar, es decir para instruir y a la vez formar a los hombres (...) describe un cambio radical que permite nacer de nuevo a otro modo de vida y de formarse según el ejemplo de CristoLogos, el huésped interior» ${ }^{15}$ de esta manera Clemente de Alejandría en su obra el Pedagogo trata de crear las condiciones de enseñabilidad ${ }^{16} \mathrm{y}$ de la capacidad de transformar las estructuras del pensamiento de quienes escuchan la Palabra de Dios y la hacen vida, pues el ser humano es capaz de conocer y actuar acorde con su experiencia y su escala de valores, lo que significa su educabilidad ${ }^{17}$.

Así, Clemente de Alejandría aporta una manera de ver cómo opera Dios en él; en una atenta audición y en una comprometida manera de enseñar, lo que significa saber quiénes son sus destinatarios, qué los mueve y cómo aprenden. En este sentido, se asume que un elemento de la experiencia fundante, señalado en la Sagrada Escritura, es la escucha a la palabra, como en los profetas, la palabra que les fue dirigida, es para ser comunicada, la palabra tiene poder y es creíble, como es creíble el amor de Dios. «Dios mismo no solo se ha tomado la tarea de crear al hombre, sino también de redimirlo y conducirlo a la salvación por medio de su acción pedagógica» ${ }^{18}$.

Con Clemente de Alejandría se puede decir que la experiencia de Dios, es una experiencia en la que Dios actúa desde dentro del ser humano. Y el ser humano es el responsable de cada acontecimiento, lo que implica ser contemplativo, estar aquí y ahora, como lo único real, sin olvidar que el momento presente está lleno de los ayeres y expectativas del mañana. Pues «tres cosas hay en el hombre: costumbres, acciones y pasiones (...) el pedagogo es educador práctico, el fin que se propone es el mejoramiento del alma, es el guía de una vida virtuosa» ${ }^{19} \mathrm{y}$

15 Hamman, A. Para leer los padres de la Iglesia, p. 48.

16 La enseñabilidad bien puede ubicarse como una construcción que hace el pedagogo a partir del estructuras conceptuales, metodológicas, estéticas, actitudinales y axiológicas, cuya intencionalidad busca despertar el aprendizaje como construcción y diálogo de saberes. En este contexto, se trata de transmitir en mensaje revelado a partir de una experiencia que es vivida y reflexionada. A partir del amor de Dios por la humanidad, de la bondad de Dios que es bueno y ama al hombre.

17 La educabilidad es la posibilidad de educar, de formar, modificar o dirigir la vida humana. Pero la educabilidad no es solo la posibilidad que tienen los hombres y mujeres de ser educados, sino que son las facultades humanas, es decir, el atributo de la "humanicidad", la aptitud para educarse.

18 De Alejandría, C. El pedagogo, p.30.

19 Ibíd., 71-73. 
asimismo dice: «Los pozos de los que se saca el agua con frecuencia la tienen más limpia y de los que no se saca nada se pudren $»^{20}$.

Es importante destacar que un elemento fundante en la experiencia de Dios, Clemente lo ubica en el bautismo. Con el bautismo se inicia la perfección del cristiano, su regeneración como hijo adoptivo de Dios, la iluminación del misterio y la interpretación de la escritura. Asimismo, ubica el conocimiento de Dios en la contemplación al estilo paulino, «conforme a la misión que Dios me concedió en vuestro favor: dar cumplimiento a la palabra de Dios, al misterio escondido desde siglos y generaciones y manifestado ahora a sus santos» (Col 1, 25-26), en este sentido la contemplación es la presencia de Cristo en nosotros, en la historia, en la vida de cada ser humano.

Asume como elemento fundante la oración, que se constituye en un diálogo con Dios, una meditación de la palabra y una acción de gracias. Hace un llamado al ser humano a divinizarse en un sentido de unificación y transfiguración, que no anula la condición humana, sino que se asimila a lo que es bello y bueno. Divinizarse significa, estabilidad en todos los sentidos, alegría y paz; reconocimiento del amor de Dios en el hombre y la mujer que los lleva a honrar a toda la creación y amar a los otros seres humanos como a sus hermanos.

Clemente, en sus escritos deja ver la experiencia de un Dios que se conmueve por el mundo que ha creado, lo sufre, lo salva y se goza en la vida encarnada en el universo. Esto es la naturaleza consecuente de Dios, verdadero Reino que está entre los hombres y mujeres. Pero también se trata de ver un Dios que goza con el universo (eros) y que se revela en él, que es fuente de felicidad y de gozo. Es la convicción de que Dios crea, corrige y salva al ser humano aconteciendo, silenciosamente, en su historia, haciéndose sensible y captable, no sólo en hechos notables y trágicos, sino, sobre todo, en la sensatez de los comportamientos de la vida personal, familiar y comunitaria ${ }^{21}$.

A su vez señala la creación como un camino que va hacia la perfección del ser humano, es decir constantemente Dios creando. También señala que en el ser humano hay un elemento divino que hace que el hombre y la mujer anhelen la semejanza con Dios y transiten un camino de perfección y de conocimiento progresivo. Esto es la pedagogía que indica que entre más el hombre y la mujer

20 De Alejandría, C. (1996). Somatra I, VIII. introducción, traducción y notas de Marcelo Merino Rodríguez. Madrid: Editorial Cuidad Nueva, p. 93.

21 González Bernal, E. (s.f). La didáctica en los métodos de la teología. Revista Anales de Teología. 
se aproximen al conocimiento de la divinidad, más cerca están de la sabiduría, la justicia y la misericordia.

Es notable la referencia al Logos - Cristo, como la causa de la existencia del ser humano y de su felicidad «El Logos que existía en el principio y del que preexistía, apareció hace un instante es el salvador preexistente, apareció el que se halla en el que existe, porque el logos estaba junto a Dios (...) enseñó a vivir virtuosamente manifestándose como maestro ${ }^{22}$. Asimismo señala la gnosis como el conocimiento de las verdades teológicas y el conocimiento a través de la contemplación de Dios, sin embargo, la gnosis no es únicamente una acción y un esfuerzo intelectual: «El gnóstico, en efecto, se caracteriza por tres cualidades: La didaskalia o enseñanza del camino, el cumplimiento de los preceptos y la contemplación (...) el fin del cristiano consiste en conocer y contemplar a Dios» ${ }^{23}$.

El Pedagogo como una obra maestra en Clemente de Alejandría evoca un saber comunicar, referido a la interrelación que con otro u otros se establece, como la índole propia de la enseñanza. Una interrelación que es transitoria (puesto que desaparece) y a la vez definitiva, en cuanto deja su huella. De esta manera, se evidencia un propósito, un sentido expresado en hacer comprensible la historia humana como historia de Salvación, lo que supone un momento comunicativo, interactivo; a través del anuncio, la comunicación, el diálogo y el compromiso. Y que a la vez lleva a descubrir a un Jesús versátil, capaz de conjugar la articulación en lo que hoy buscamos entre teoría y praxis, entre saber y saber hacer, entre saber comunicar y saber evaluar.

La preocupación que presenta Clemente de Alejandría con El Pedagogo, son unas enseñanzas ${ }^{24}$ intermedias que parten de la conversión hasta llegar a la perfección en Dios. Pone aquí la función de la educación como un proceso de curación de las enfermedades, pero señala que «El Logos del Padre es el único médico de las debilidades humanas, es curador y santo ensalmador del alma enferma: levántate toma la camilla sobre la que estás tendido y vete a casa (...) tus pecados

22 De Alejandría, C. (2008). Protréptico, I, 6,5-7,5. Introducción, traducción y notas de Marcelo Merino Rodríguez. Madrid: Editorial Cuidad Nueva, 77-81.

23 L. Borriello, E. Caruana, M.R. Del Genio, N. Suffi. Diccionario de Mística: 420. Aquí mismo se señala que el gnóstico honra tanto el cuerpo como el mundo y reconoce en ello la obra de Dios, ama pues a sus hermanos con un caridad que abarca las necesidades del cuerpo y las del alma. Cuando el amor ha alcanzado la perfección es unión íntima con Dios.

24 Toda la obra deja ver que es una continuidad en la Paideia griega. 
te son perdonados (...) salva Dios mío a tu siervo que confía en ti», ${ }^{25}$ lo que muestra una acción que lleva a concebir a un Dios-bueno, que ama al ser humano, lo cura, lo perdona y lo educa.

En este contexto, Clemente de Alejandría con su trilogía: Protéptico, el Pedagogo y los Stromata, nos relata que es en la vida cotidiana, en cada acontecimiento, en detalles muy concretos, en comportamientos y en circunstancias, donde el cristiano debe posibilitar la experiencia y encuentro con su creador. Donde el cristiano debe estar pendiente de su vida, de sus acciones, de su propio cuidado por no hacerse daño. Lo que bien puede llamarse una experiencia de una pedagogía del cuidado en su vida diaria. Desde luego que no deja de lado lo que inspira la unión con Dios: lectura de la Sagrada Escritura, la oración y la contemplación, como él mismo lo decía «La pedagogía divina es la que lleva a la contemplación de Dios», ${ }^{26}$ pues todos los medios están dados; ayudas y favores de Dios, para no vivir en las adicciones y apegos hacia aquello que nos daña por dentro y nos lleva hacer el daño a los demás y a la naturaleza.

Es notable la referencia constante que hace Clemente de Alejandría a la Sagrada Escritura con un estilo particular de saber hacer las preguntas al texto bíblico, más allá de un ejercicio académico, o un reto científico, es una manera de enseñar lo que sabe fruto de la experiencia y la reflexión. Es amplia la presentación que hace sobre fe y filosofía. A él le interesa mostrar la manera como la filosofía, abre, indica y predispone el camino a la perfección de Cristo y, para ello, se apoya en el libro de los proverbios, «El comienzo de la sabiduría está en adquirirla y obtener inteligencia con toda tu fortuna. Hónrala y ella te engrandecerá, si la abrazas te dará prestigio» (Pr 4,7).

Asimismo muestra que la filosofía es un paso a la verdadera sabiduría y que por tanto hay que saberla cuidar, protegerla de falsas elucubraciones (contra los sofistas), pues ella es útil para comprender la verdad revelada «¿Por qué apasionarte hijo mío, de una extraña y caer en brazos de una desconocida?» (Pr 5,20), lo que se busca es una mejor comprensión de la fe, que es producto del aprendizaje, un cuidado por no caer en la falsa mentira y en el autoengaño.

Ahora bien, los elementos fundantes que Clemente presenta como experiencia de Dios, están dados en la capacidad que tiene el ser humano para conocer

25 De Alejandría, C. (1998). El pedagogo. Traducción y notas por Joan Sariol Díaz. Madrid: Editorial Gredos, p. 46.

26 De Alejandría, C. (1998). El pedagogo. Edición bilingüe preparada por Marcelo Merino y Emilio Redondo, p. 187. 
(gnosis) lo que se traduce en un experimentar a Dios, amor, amistad, palabra, sabiduría. Pero, para llegar a este conocimiento de Dios, es necesaria la comprensión racional y la meditación de la Sagrada Escritura. Es necesaria la contemplación que conduce a la familiaridad con Cristo, al conocimiento interno del Señor y a su amor, «El que tiene mis mandamientos y los llevará a la práctica, ése es el que me ama; y el que me ame será amado de mi Padre y yo le amaré y me manifestaré a él» (Jn 14, 21), de esta manera Jesús es el camino o el método para llegar al Padre; su conocimiento de mediado por el amor, por el afecto, la familiaridad y la intimidad. Lo que constituye que en la cumbre del verdadero conocimiento de Dios está el afecto y el afecto lleva a la oración de encuentro pleno y de sentimiento de unión.

\section{La experiencia de Dios en San Agustín de Hipona.}

San Agustín de Hipona ${ }^{27}$ es un hombre con una experiencia profunda de conversión que lo hizo ser un apasionado por su conocimiento personal y por el conocimiento de cómo Dios actúa en el ser humano. Su pensamiento filosófico lo llevó a presentar sus reflexiones cuyo fondo fueron la relación entre razón y fe Crede aut intelligas et intellige ut credas (cree para entender y entiende para creer) (sermón 43.9), asimismo «su pensamiento teológico se inspira en un método que incluye la adhesión a la autoridad de Cristo, el deseo de conocer el contenido de la fe, el sentido del misterio y la convicción de la originalidad cristiana o depositum fidei, que hay que conservar y defender si es necesario» ${ }^{28}$.

En este sentido centramos la atención en los elementos fundantes que constituyen su experiencia de Dios. San Agustín revela en primer lugar que saberse amado por Dios, significa un cambio radical en la vida, que él llama conversión. Pero para que este cambio se dé es necesario tener un conocimiento de Dios, y, ese conocimiento, se encuentra en la Sagrada Escritura.

27 Laporte, J. (2004). Los padres de la Iglesia. Padres griegos y latinos en sus textos. Madrid: San Pablo. Este autor al referirse a San Agustín dice: «Agustín (354-430) Obispo de Hipona localidad del norte de África, es el principal teólogo de la Iglesia Oriental. Agustín constituyó la fuente y la autoridad sobre las que se apoyó Tomás de Aquino como representante de la tradición cristiana (...) la mejor manera de adentrarse en el maravilloso templo espiritual del pensamiento teológico de San Agustín es comenzar por el célebre relato de las confesiones, para ver como Agustín creció en la gracia de Dios y fue por ella liberado de los lazos de la carne» cfr: 233.

28 Patiño, U. (2005). Los padres de la Iglesia. Una tradición como búsqueda teológica. Bogotá: San Pablo, p. 100. 
Es notable en San Agustín que por el conocimiento se llegue al reconocimiento de la autoridad de Dios, «Dame, Señor, a conocer y entender qué es primero, si invocarte o alabarte, o si es antes conocerte que invocarte. Mas ¿quién habrá que te invoque si antes no te conoce? Porque, no conociéndote, fácilmente podrá invocar una cosa por otra» ${ }^{29}$. Es la necesidad de la gnosis, solo se invoca, se alaba y se ama a quien se conoce «No se puede amar lo que se ignora por completo, pero, cuando se ama lo que de algún modo se conoce, en virtud de ese amor se llega a conocerlo mejor y más en profundidad $»^{30}$.

La experiencia de San Agustín revela un cambio en su vida y una conversión permanente. Un cambio de vida y la certeza de que algo nuevo pasaba en su ser, que lo llevó a asumir un camino con Jesús. Un seguimiento radical y un amor que dio sentido y plenitud a su vida. Aunque en ese caminar con Jesús muchas veces le fue difícil, él supo mantenerse aun sabiendo que las certezas eran sus mayores dudas. Porque seguir a Jesús es transitar un camino signado por la cruz. Un camino en el que el silencio de Dios se hace presente «Nunca he sabido a quien me dirigía cuando interpelaba a Dios» ${ }^{31}$. Pero sobre todo es un camino en el que se experimenta y se sabe acompañado por una fuerza misteriosa que anima, consuela y sostiene.

San Agustín interpreta que Dios «porta en sí el secreto del hombre, en quien tiene incluso en su propio cor su morada (...) se encuentra con Dios del que alejarse es caer, al que dirigirse es resurgir, en el que permanecer es estar seguro, al que volver es renacer, en el que habitar es vivir ${ }^{32}$. La interpretación que hace el santo es una invitación a descubrir una forma más profunda de comprender y de comprenderse. Desde esta perspectiva la revelación no se da como un dato que se enuncia, sino una experiencia de una llamada que se acepta, una llamada a ser en el mundo y a estar en el tiempo desde Dios.

En el libro X, de la Confesiones, San Agustín empieza diciendo: «Conózcate a ti, conocedor mío, conózcate a ti como soy conocido. Virtud de mi alma, entra

29 San Agustín. (1951). Obras de San Agustín. Tomo II. Las Confesiones. Texto bilingüe, edición crítica y anotada por Angel Custodio Vega. Madrid: Biblioteca de Autores Cristianos, p. 83.

30 L. Borriello, E. Caruana, M.R. Del Genio, N. Suffi. Diccionario de Mística: 89. La cita que trae el diccionario es tomada del libro de las confesiones de San Agustín.

31 Benzo, M. (1978). Hombre profano-hombre sagrado. Tratado de Antropología Teológica. Madrid: Ediciones Cristiandad, p. 37.

32 L. Borriello, E. Caruana, M.R. Del Genio, N. Suffi. Diccionario de Mística, p. 90. 
en ella y ajústala a ti, para que la tengas y poseas sin mancha ni ruga $»^{33}$. Todo el libro expresa la motivación del santo por confesarse ante Dios y ante los hombres. Presenta la invocación al conocimiento de si, de lo que lo habita y a la necesidad de reconocerse necesitado de conocimiento: “Agustín quiere clarificarse acerca de lo que puede significar confesarse ante Dios a quien dada su infinita sabiduría nada puede quedarle oculto a quien en realidad nada cabe consecuentemente comunicar que no sepa él ya de antemano (...) así pues Agustín se propone dar cuenta de si y solo confesará lo que sabe de sí mismo. También reconoce que no lo sabe todo sobre si mismo, también eso quiere confesarlo" (Heidegger, 1995, p. 45). ${ }^{34}$

San Agustín nos deja ver el problema de lo humano, la captación e interpretación de la condición humana en relación con lo divino. La originalidad de su confesión es la certeza de saberse ante quien se confiesa y que ese, ante quien se confiesa es capaza de guiarle, de activarle la luz que yace dentro «He aquí que amaste la verdad, porque el que la obra viene a la luz. Quiérola yo obrar en mi corazón, delante de ti por esta mi confesión y delante de muchos testigos por este mi escrito» ${ }^{35}$. Esto es lo que bien puede llamarse una acción pedagógica, en el sentido de que el camino recorrido produce confianza y se llega al conocimiento.

De esta manera San Agustín aporta elementos pedagógicos para un ejercicio permanente de interrogarse por el ser que experimenta a Dios a partir de un seguimiento, de una experiencia interior que no podemos rechazar, de una experiencia que puede ser comunicada, descrita por cada creyente en forma diferente, como cada artista describe su propia experiencia, pues no se trata de demostrar a Dios sino de mostrarlo. En este mismo sentido Schillebeeckx, indica un camino de conocimiento de Cristo en la medida que: «rehacemos su camino, que lo seguimos fielmente, solo así conocemos en qué consiste el Reino de Dios y su justicia» ${ }^{36}$. En San Agustín hay una llamada, tal vez, anónima, que lleva a

33 San Agustín. Obras de San Agustín. Tomo II Las Confesiones Libro X.1. En el 38, dice: ¡Tarde te amé, hermosura tan antigua y tan nueva, tarde te amé! $Y$ he aquí que, Tú estabas dentro de mí y yo fuera, y por fuera te buscaba; y deforme como era, me lanzaba sobre estas cosas hermosas que tú creaste. Tú estabas conmigo, mas yo no lo estaba contigo. Reteníanme lejos de ti aquellas cosas que, si no estuviesen en ti, no serian. Llamaste y clamaste, y rompiste mi sordera; brillaste y resplandeciste, y fugaste mi ceguera; exhalaste tu perfume y respiré, y suspiro por ti; gusté de ti, y siento hambre y sed, me tocaste, y abraséme en tu paz.

34 Heidegger, M. (1995). Estudios sobre mística medieval. Traducción de Jacobo Muñoz. Madrid: Ediciones Siruela, p. 45.

35 San Agustín. Obras de San Agustín. Tomo II Las Confesiones Libro X.1

36 Schillebeeckx, E. (1973). Interpretación de la fe. Aportaciones a una teología hermenéutica y crítica. Salamanca: Sígueme, p. 219. El autor señala que la teología sin fe no aduce más que a 
la interpretación y a la respuesta de la que es capaz el hombre y la mujer de dar sin entrar en explicaciones. Es una llamada que permite interiorizar en la vida misma y que genera una experiencia dinámica de conversión y de comunión con el universo en general.

San Agustín tiene una invitación constante hacia el conocimiento de Dios, y es que en el hombre y la mujer habitan la pregunta y la respuesta, la certeza de la existencia como producto del acto del pensar y de la memoria. Invita a la conversión de la inteligencia, pues es dolorosa la insuficiencia para conocerse a sí mismo «Tú señor me trastocabas a mí mismo, quitándome de mi espalda, a donde yo me había puesto para no verme, y poniéndome delante de mi rostro para que viese cuán feo era, cuán deforme y sucio, manchado y ulceroso ${ }^{37}$, es la invitación a que la razón sepa medir su soberbia, agachar la cabeza para así comprender en este sentido que los publicanos y las prostitutas nos precederán en el Reino de los cielos (Mt 21,31), pues ellos se han despojado del orgullo de la razón.

Es también la invitación a proteger la vida interior de las asechanzas, que como bien lo interpreta Santa Teresa en la imagen del Castillo Interior, ${ }^{38}$ el ser humano debe conocerse y cuidarse. Se trata de asumir una vida en la que hay un donante y un donado «No obtengo nada más que una existencia, y una existencia de verdad desértica, puro producto de una duda hiperbólica, sin intuición, sin concepto y sin nombre: un desierto, el fenómeno más pobre que no sabe dar más que su vaciedad $»^{39}$. Se trata de captar el todo para poder ser conscientes de la armonía y para ello es necesario el cuidado de lo espiritual para contemplar

un sin sentido, y una fe sin teología pierde todo crédito y se hace irrelevante. La hermenéutica para este autor es ante todo experiencia de la acción de Dios en la historia de los seres humanos.

37 San Agustín. Obras de San Agustín. Tomo II Las Confesiones Libro III.4,7.

38 Santa Teresa de Jesús. (1963). Obras completas. Editadas y anotadas por el padre Silverio de Santa Teresa. Madrid: Aguilar S.A, Al referirse al castillo interior la Santa dice: Fuera del mundo, las moradas que rodean el castillo, se extiende el mundo exterior, en la instancia más interior habita Dios. Entre estos dos extremos se hallan las seis moradas que circundan la más interior (la séptima). Pero los moradores que andan por fuera o se quedan junto al muro de cerca, no saben nada del interior del castillo. Cosa extraña que uno no conozca su propia casa, pero de hecho hay muchas almas así, tan enfermas y mostradas a estar es en cosas exteriores, que no hay remedio, ni parece que pueden entrar dentro de sí, porque ya la costumbre la tiene tal de haber siempre tratado con las sabandijas y bestias que están en el cerco del castillo, que ya casi está hecha como ellas. A estas almas han desaprendido a rezar y sin embargo la puerta para entrar en este castillo es la oración y consideración. Pues para que la oración merezca tal nombre, uno ha de advertir con quién habla y lo que pide y quién es quien lo pide y a quién.

39 Marion, J.L (2007). El fenómeno erótico. Roma: Cantagalli, p. 31. 
aquello en lo que pueden ser tocados profundamente los hombres y las mujeres, para saber dónde está la fuente que lleva a la plenitud y a la unión con Dios.

La clave en la experiencia de Dios en San Agustín es la conversión, que puede interpretarse como: seguimiento a Jesús, aceptación de la voluntad de Dios, transformación interior, aceptación de una llamada de Dios, un acometimiento contra las adicciones, vicios, dependencias, un paso decisivo de un estado de pecado a un estado de gracia de Dios. Lo que se percibe también es un cambio de vida y un camino de cuidado y desarrollo de la vida espiritual. En este contexto, el cambio de orientación en la vida y de arrepentimiento conlleva a una vivencia moral, hacia un movimiento ascendente metanoia mayor en un mejor estado de vida, hacia la verdad y el bien.

San Agustín pedagógicamente propone un esquema de conversión creatioconversio-formatio, presente especialmente en su tratado de Trinitate ${ }^{40}$. Aquí señala la conversión como un acto primero y como proceso, es decir, sucesivas conversiones durante la vida del ser humano. Esto se traduce en que el hombre y la mujer han sido obra de Dios; hechura de sus manos, creaturas, con libertad para elegir, pero que en su debilidad eligen en muchas ocasiones el mal en lugar de elegir la plenitud y el sumo bien, entonces se debe asumir o vivir la experiencia de la conversión para llegar a la plenitud o formatio, que es la unificación de lo que está disperso en el humano, es el dejarse dar forma o moldearse desde Dios.

Asimismo se trata de llevar a cabo un perfeccionamiento intelectual y espiritual. Para San Agustín la vida intelectual debe llevar al cristiano a un mayor conocimiento del amor de Dios y a reconocerse iluminado por él. A reconocer al maestro interior que habita en el ser humano y enseña: «El maestro interior es quien enseña: Cristo enseña, su inspiración enseña. Donde no están su inspiración ni su unción, vanamente suenan en el exterior sus palabras ${ }^{41}$, el santo asocia la enseñanza con la curación, lo que llama él la sana doctrina. Importante destacar que en su obra De Magistro relaciona la palabra con la enseñanza, propio de alguien que ha tenido una experiencia de la verdad que exige ser comunicada.

Aunque San Agustín reconoce en De Trinitate, que el silencio siempre se impone, y que cuando esto ocurre Dios se expone, así lo expresa: «En el momento de hablar de cosas de las que nadie - al menos yo - no puedo expresar la idea de que Dios tiene de ellas (...) es ante todo en ese Señor Dios dueño nuestro, en quien

40 San Agustín. (1948). Obras completas. Tomo V Tratado sobre la Santísima Trinidad. Edición bilingüe. Introducción y notas de Fray Luis Arias. Madrid: Biblioteca de Autores cristianos.

41 San Agustín. Obras de San Agustín. Tomo XIX De Magistro, 4, 6. 
debemos pensar siempre, sin poderlo pensar dignamente, a quien junto con la alabanza, se debe en todo momento la bendición (...) para hablar de lo inefable hay que decirlo como uno pueda ${ }^{42}$. En este sentido San Agustín «No encierra la teología en el silencio de una mística de fusión que desorienta: ausencia de discurso más grave aún que su exuberante presencia (...) ante este Señor nuestro pido ayuda para comprender y explicar» ${ }^{43}$.

Elemento común en la experiencia de Dios es la comunicación de lo que se ha sentido y vivido, de ahí que comunicar se relacione con la pedagogía ${ }^{44}$. Los santos desembocan en un acto de enseñanza; cuando se está lleno de algo (Dios) es imposible callar, la palabra rebosa, por ello se asocia a diferentes figuras, entre ellas, a la de manantial, que brota, que es agua y vida para todos.

\section{Conclusiones}

En el desarrollo de la teología de los padres de la Iglesia aquí mencionados, encontramos que, quien ama a Dios, ingresa en el dinamismo de una aspiración incesante y en lo concreto de muchas ocasiones, en una verdadera carrera de obstáculos y sufrimientos detrás de Él. Pero, el Señor siempre se adelanta y atrae hacia sí, poderosamente; hace comprensible la experiencia, hace caer en cuenta «Qué torpes sois y tardos para entender lo que dijeron los profetas ¿no era necesario que Cristo sufriera todo eso para entrar en su gloria?» (Lc 24,25).

Para llegar a la comprensión es necesario un conocimiento obtenido, que parte de la meditación de la Sagrada Escritura y que da la predilección por la humanidad de Cristo, de una doctrina amorosa, en la que la amistad sella un pacto de amor mutuo-amistad, y por la "alianza" bíblica. Es un conocimiento que se da

42 San Agustín. Obras completas. Tomo V Tratado sobre la Santísima Trinidad. Prologo.

43 Falque, E. (2012). Dios, la carne y el otro. De Ireneo a Duns Escoto: Reflexiones fenomenológicas. Traducción de Martha González y Jorge Aurelio Díaz. Bogotá: Siglo del Hombre Editores, p. 89.

44 Laporte, J. Los padres de la Iglesia. Padres griegos y latinos en sus textos: 248. Al hacer un comentario sobre De Magistro dice: necesitamos signos (palabras) para pensar y comunicarnos con el exterior, pero estos signos no bastan a menos que se alimenten de los datos que provienen de la reminiscencia o de la evidencia directa. Además en el nivel más elevado de los números espirituales, no entendemos estos datos por la comunicación propiamente exterior, sino porque la verdad en la persona reside en nuestro interior, por encima de nuestro espíritu: es Cristo sabiduría de Dios. Y el maestro espiritual nos revela la verdad según nuestra capacidad y nuestras buenas disposiciones. 
por medio de una revelación divina y que es distinto al conocimiento obtenido por el discurso mental o por la aceptación del saber de otro.

En este sentido, la experiencia es una comprensión que abarca la dimensión humana, en la que experimentamos la presencia dinámica y misericordiosa de Dios, que nos mueve a descubrir el misterio amoroso en la cotidianidad de la vida y a hacer de la conciencia histórica el fundamento de la comprensión de cualquier mensaje. Hablar de la experiencia de Dios es recuperar la dimensión contemplativa de la existencia cristiana, como lo afirma Boff y Betto «Espiritualidad y mística, salvación y esperanza forman parte de la vida en su integridad y sacralidad $»^{45}$.

Por tanto el quehacer teológico es entendimiento, comprensión y acción. Lo que indica una lógica en la manera de percibir la vida, de reflexionar y de entender la fuente de su existencia con el misterio de Dios. Es sentir y experimentar la filiación de Dios «Tu eres mi hijo amado, en ti me complazco» (Mc 1,11) y es también la experiencia de sentirse impulsado a comunicar «El Espíritu del Señor me ha ungido y me ha enviado a anunciar» (Lc 4,18).

\section{Referencias}

Barth, K. (2006). Introducción a la teología evangélica. Barcelona: Sígueme.

Benzo, M. (1978). Hombre profano-hombre sagrado. Tratado de Antropología Teológica. Madrid: Ediciones Cristiandad.

Boff, L., Betto. (2002). Mística y espiritualidad. Madrid: Trotta.

Borriello, L., Caruana, E., Del Genio, M.R., Suffi, N. (1997). Diccionario de Mística. San Pablo, del 2002

De Alejandría, C. (1994). El pedagogo. Edición bilingüe preparada por Marcelo Merino y Emilio Redondo. Madrid: Editorial Ciudad Nueva.

(1996). Somatra I, VIII. Introducción, traducción y notas de Marcelo Merino Rodríguez. Madrid: Editorial Cuidad Nueva.

(2008), Protréptico, I, 6,5-7,5. Introducción, traducción y notas de Marcelo Merino Rodríguez. Madrid: Editorial Cuidad Nueva.

Durwel, F.X. (1972). La presencia de Jesucristo en la predicación. España: Salamanca.

45 Boff, Leonardo; Betto, Frey. Mística y espiritualidad. Madrid: Trotta, 2002: 13. 
Duquoc, Chistian O.P. (2006). El destierro de la teología. El reto de su supervivencia en la cultura contemporánea. Bilbao: Mensajero.

Falque, E. (2012). Dios, la carne y el otro. De Ireneo a Duns Escoto: Reflexiones fenomenológicas. Traducción de Martha González y Jorge Aurelio Díaz. Bogotá: Siglo del Hombre Editores.

González Bernal, E. (2010). La didáctica en los métodos de la teología. Revista Franciscanum.

González Faus, J.I. (1985). La libertad de palabra en la Iglesia y en la teología. Santander: Sal Terrae.

Gutiérrez, G. (1985). Beber en su propio pozo. Salamanca: Sígueme.

Hamman, A. (2009). Para leer los padres de la Iglesia. Bilbao. Editorial DDB.

Heidegger, M. (1992). ¿Qué es la metafísica? Y otros ensayos. Traducción de Xavier de Zubiri, Buenos Aires: Fausto. 1995). Estudios sobre mística medieval. Traducción de Jacobo Muñoz. Madrid: Ediciones Siruela.

Laporte, J. (2004). Los padres de la Iglesia. Padres griegos y latinos en sus textos. Madrid: San Pablo.

Marion, J.L. (2007). El fenómeno erótico. Roma: Cantagalli.

Patiño, U. (2005). Los padres de la Iglesia. Una tradición como búsqueda teológica. Bogotá: San Pablo.

San Agustín. (1948). Tomo V. Tratado sobre la Santísima Trinidad. Edición bilingüe. Introducción y notas de Fray Luis Arias. Madrid: Biblioteca de Autores cristianos. (1951). Obras de San Agustín. Tomo II. Las Confesiones. Texto bilingüe, edición crítica y anotada por Angel Custodio Vega. Madrid: Biblioteca de Autores Cristianos.

San Agustín. Obras de San Agustín. Tomo II. Las Confesiones Libro X.1.

Tomo II. (1849) Las Confesiones Libro X.1 Bogotá. Librería religiosa.

Tomo II. (1849) Las Confesiones Libro III. Bogotá. Librería religiosa.

Tomo XIX. De Magistro, 4, 6.

Tomo V. (1956) Tratado sobre la Santísima Trinidad. Prologo. Madrid Biblioteca de autores cristianos. Editorial Católica S.A.

Santa Teresa de Jesús. (1963).Obras completas. Editadas y anotadas por el padre Silverio de Santa Teresa. Madrid: Aguilar S.A.

Schillebeeckx, E. (1973). Interpretación de la fe. Aportaciones a una teología hermenéutica y crítica. Salamanca: Sígueme.

Schneider, M. (2000). Teología como biografía. Una fundamentación dogmática. España. Desclée de Brouwer 
Sudbrack, J. (2004). El espíritu es concreto: la espiritualidad desde una perspectiva cristiana. Bilbao: Mensajero.

Unamuno, M. (1996). Diario íntimo. Obras completas, t. 8, Madrid: Biblioteca Castro Fundación José Antonio de Castro. 